\title{
Czech University Students' Use of Study Resources in Relation to the Approaches to Learning
}

DOI: 10.15804/tner.2019.56.2.09

\begin{abstract}
The paper reports on an empirical survey aiming to find out what study resources university students use and whether the frequency of the use of specific resources is related to deep and surface approaches to learning. An exploratory survey was carried out using two instruments - the ASSIST questionnaire adapted for Czech students and a newly designed questionnaire The Use of Study Resources. The sample consisted of 2,671 students from six faculties. Results showed that the most frequently used resources were students' own notes from lectures and seminars, presentations created by teachers and course readers. Statistical analysis proved that there is a relation between the frequency of the use of study resources and the student's approach to learning.
\end{abstract}

Keywords: study resources, use of study resources, approaches to learning, university students

\section{Introduction}

Over the last decades, higher education pedagogy has been intensively developing, among other things, in connection with dramatic changes in higher education. In this vast research field, many studies also deal with teaching and learning resources. Given the nature of university students' learning, based mainly on self-study and students' individual preparation, it is clear that study resources play an essential role in higher education. With regards to the dynamic entrance 
of information technologies into higher education, it is natural that the majority of current research dealing with study resources at universities focus on the comparison of the use of printed and digital materials, the effectivity of learning from different formats and students' preferences in this regard. Apart from this strong thematic stream, or within it, there also sporadically appear studies directly dealing with the use of study resources and university students' learning habits. The empirical research reported in this article is a part of long-term research on students' learning habits and the use of educational media and study resources in teaching and learning at the University of Ostrava.

\section{Research Questions}

The paper presents selected results related to the questions: 'What types of study resources do university students use while preparing for an exam or a test?' and 'Is there a relationship between the frequency of the use of study resources and students' approaches to learning?' The main hypotheses focused on ascertaining whether there is a relationship between the frequency of the use of specific types of study resources and students' deep/surface approach to learning.

\section{Theoretical Background}

The theoretical part will present findings from research carried out in the field of the use of study resources at universities. First, the results of the research studies focusing on different types of study resources used by university students will be introduced and then the theory of students' approaches to learning upon which the research builds will be explained.

Research studies examining which particular type of resources university students use when preparing for courses, working on assignments and preparing for tests and exams appear only sporadically. For the purposes of this study, study resources are defined as any text resources, including iconic ones, which serve as a source of knowledge or means to learn course content. Nowadays, this includes a wide spectrum of study resources. There seem to be at least four types: (a) didactic published materials, e.g., textbooks, course readers and others, (b) highly specialised publications from a given field like monographs, articles, encyclopaedias and handbooks, (c) materials which teachers give to students and which are mostly available online, e.g., PowerPoint presentations, lectures in the 
form of a text, audio or video, sample tests, links to websites, webinars and many other curricular resources, (d) and materials created by students themselves, such as their own notes from lectures and jointly prepared exam topics or materials made by other students and shared.

While there are few sources available, a number of papers discuss results relevant for our study. Students tend to rely on textbooks, lecture notes or teachers' presentations shared electronically, their own notes from lectures and online sample tests (Huon, Spehar, Adam \& Rifkin, 2007; Pecorari, Shaw, Irvine, Malstrom \& Mežek, 2012). It is interesting that students' attitudes to textbooks are rather positive. However, Pecorari et al. found that students' behaviour is inconsistent with these attitudes: textbooks are valued resources, but they use lecture notes provided by teachers and their own notes more often. Horsley, Knight and Huntly (2010) and Horsley and Huntly (2011) found out that students used textbooks, course readers and a great number of additional materials accessible from the university Learning Management System. The use of commercially published textbooks differed according to the degree of the centrality of the resource - the importance of the resource for successful completion of the course and its position within the scope of other used resources from a core resource to a peripheral resource.

The concept and diagnostics of students' approaches to learning in our research are based on the theory of approaches to learning drawn upon the pivotal study by Marton and Säljö (e.g., 1997). The main difference between the deep and surface approach is in the intention - to either reproduce presented material or to understand it (Entwistle, 2009). The search for meaning in the deep approach is primarily based on relating learning to previous knowledge and experience, verifying evidence and critical examination of logic and arguments. The surface approach, on the other hand, is characterised by the intention to handle the course requirements. The main means is reproduction, which leads to routine memorisation of facts or steps, conceiving the course content as random pieces of knowledge and learning without thinking about its purpose or strategy. While deep and surface approaches represent the main dichotomy in approaches to learning, the strategic approach is an additional category (Entwistle \& Ramsden, 1983), which takes into consideration the effect of formal assessment. 


\section{Research Methodology}

Given the lack of research findings regarding the use of study resources and study habits in university students and given that the aim was to verify if there are differences in the use of study resources and students' study habits, an explorative quantitative survey was carried out. Data were collected using two questionnaires - Students' Approaches to Learning, Czech version adapted from the original British ASSIST tool (Approaches and Study Skills Inventory for Students, 2005) and our own instrument The Use of Study Resources.

\section{Research Sample}

Data collection was carried out at all faculties of the University of Ostrava from December 2017 to February 2018. Questionnaires were distributed electronically by vice-deans or in paper form by academic staff to all students. After the elimination of incompletely filled-in questionnaires, a total number of 2,671 questionnaires was obtained ( $25.2 \%$ in digital form, $74.8 \%$ in paper form). The largest proportion in the research sample represented students from the Faculty of Education $(n=1127)$ and Faculty of Medicine $(n=882)$, where we managed to gather a number of respondents corresponding to approximately a half of the real number of students enrolled in these faculties in the given academic year. The other faculties included Faculty of Social Studies $(n=202)$, Faculty of Fine Arts $(n=90)$, Faculty of Arts $(n=161)$ and Faculty of Sciences $(n=209)$. The sample predominantly consisted of Bachelor's degree students (64.3\%), five-year Master's course students represented $19.4 \%$ and two-year Master's course students 16.2 $\%$. The sample included both full-time $(74 \%)$ as well as part-time students (26 $\%)$ from all years. With regards to the recommended sample size corresponding to the size of the basic sample in terms of validity (Chráska, 2016), the minimum numbers of data needed for the sample were reached, with the exception of tests including the variable 'faculty'.

\section{Instruments and Procedures}

To diagnose the deep, surface and strategic approach to learning, we used the ASSIST questionnaire (Approaches and Study Skills Inventory for Students, 2005). Throughout the years, the questionnaire was verified and modified by the team of authors from the University of Edinburgh as well as by other researchers. Its validity was examined in many different countries and cultures (Entwistle, Tait \& McCune, 2000; Diseth, 2001; Byrne, Flood \& Willis, 2004 and others). According to the authors' analyses, it became apparent that three ASSIST scales, i.e., the scale 
of deep, surface and strategic approaches can provide more valid indicators than other similar instruments.

The research survey presented in this article draws on our long-term research among students of education carried out since 2013, when we used the instrument in a pilot survey for the first time. The original questionnaire in English consisted of 52 items; a later version with 36 items was used for the adaptation. Items are in the form of a statement and students express their agreement with them on a fivepoint Likert-type scale. When we received the authors' approval to adapt ASSIST for the Czech environment, we arranged its professional translation into Czech and also back translation from Czech into English. The sample for the adaptation of the questionnaire consisted of students from the Faculty of Education from the University of Ostrava $(n=299)$. Confirmatory factor analysis (CFA) was applied on the collected data and it confirmed that originally selected factors are sufficiently saturated, except for four items: A17, A19, A20, and A34. Consequently, these items were not included in the final version with respect to the factor loadings in rotated factor matrix. After we received the respondents' answers, a new questionnaire structure was again subjected to the confirmatory factor analysis. Both factor analyses were based on the method of Principal Components and the method of element rotation called VARIMAX was also used in order to better interpret results from the CFA. The final Czech version of the instrument consists of 32 items. As for the 'deep approach' scale, the value of Cronbach's alpha coefficient of reliability was $\alpha=0.786$, for the 'surface approach' $\alpha=0.743$ and for the 'strategic approach' $\alpha=0.731$, which can be considered acceptable.

'The Use of Study Resources' questionnaire was constructed based on findings from research studies dealing with study resources and students' habits. Topics of the USR include sections focusing on the frequency of the use of study resources, factors influencing the choice of resources, ways of the resources use and procedures applied while learning form text. These topics were saturated with 47 items of the Likert-type scale. Study resources can be divided into four groups: published didactic texts primarily intended for teaching and learning, academic publications, texts written by teachers or students, and specific digital resources such as webinars, video tutorials, e-courses, etc. (cf., Table 1). The value of Cronbach's alpha coefficient of reliability for this questionnaire was $\alpha=0.789$.

\section{Statistical Data Analysis}

Before the test of hypotheses, the analysis of normality of data under consideration was carried out using the Shapiro-Wilk and Anderson-Darling procedures. As expected, the data were not normally distributed in all tests. Therefore, the 
Kruskal-Wallis nonparametric test was chosen for the test of hypotheses followed by post-hoc tests. If the null hypothesis was rejected, the test power characteristics $1-\beta$ was set, which was demonstrable at $1-\beta>0.8$. Statistic processing was also supplemented by Partial Eta-Squared effect size $\eta^{2}$. The effect size significance could be assessed according to an interval: small effect $\eta^{2}>0.0099$, medium $\eta^{2}$ $>0.0588$ and large effect size $\eta^{2}>0.1379$ (Richardson, 2011). Statistical analyses were carried out in the SPSS software version 25.

\section{Research Results}

\section{Types of study resources used by students}

The study resources from which the students learned to prepare for tests and exams is presented in Table 1 . The median values of the five-point scale representing the frequency of the use from ' 1 -never' to ' 5 -all the time' and post-hoc tests showed that there are basically four groups of study resources from the most frequently used to the least frequently used.

Table 1. The order of the types of resources according to the frequency of use

\begin{tabular}{lllll}
\hline \multirow{2}{*}{ Order } & \multicolumn{1}{c}{ Type of a resource } & $\bar{x}$ & $\sigma$ \\
\hline 1. & Students' own notes from lectures/seminars & 4.45 & 5 & 0.91 \\
\hline 2. & Presentations created by teachers & 4.27 & 5 & 0.99 \\
\hline 3. & Course readers & 4.17 & 5 & 1.05 \\
\hline 4. & Exam topics prepared by other students & 3.94 & 4 & 1.25 \\
\hline 5. & Exam topics prepared jointly & 3.84 & 4 & 1.34 \\
\hline 6. & University textbooks & 3.21 & 3 & 1.33 \\
\hline 7. & Monographs, academic books & 2.95 & 3 & 1.31 \\
\hline 8. & Unverified Internet resources, e.g., Wikipedia & 2.87 & 3 & 1.31 \\
\hline 9. & Study support for distance courses & 2.63 & 2 & 1.46 \\
\hline 10. & Reference books like dictionaries and encyclopaedias & 2.58 & 2 & 1.27 \\
\hline 11. & Academic articles & 2.42 & 2 & 1.16 \\
\hline 12. & Webinars, video tutorials, e-courses & 2.08 & 2 & 1.26 \\
\hline
\end{tabular}

Note: $\bar{x}$-arithmetic mean, $\tilde{x}$ - median, $\sigma$-standard deviation. 
According to the students, the most frequently used resources were 'their own notes from lectures or seminars/workshops', 'presentations created by teachers' and 'course readers'. As for their own notes, almost $90 \%$ of the respondents chose the maximum values 4 or 5 , and as for presentations and university textbooks, it was approximately $80 \%$ of the respondents. Other very frequently used resources proved to be prepared exam topics. 'Exam topics prepared by other students' are those which students obtain without their own contribution; they often do not even know who wrote them. Students often receive them from students in years ahead of them. 'Exam topics prepared jointly' are regarded as a set of materials which is created by students - often from one study group - who split all the topics assigned for an exam among themselves and then each of them prepares excerpts or summary for a given topic or topics which are then shared.

The frequency of the use of 'university textbooks' and 'monographs' reached similar values. According to the students, more than a half of them never or hardly ever used textbooks (they chose value 1 or 2 on the scale) and this also applies to $40 \%$ of the students for monographs. The least used types of resources were 'electronic webinars, video tutorials, e-courses and others', 'academic articles' and a reference-type of books such as 'dictionaries and encyclopaedias'. Approximately a half of the respondents chose value 1 or 2 on the scale for dictionaries and encyclopaedias, which means that they never or hardly ever use them; about $40 \%$ of the students never or hardly ever used academic articles.

\section{The frequency of the use of study resources in relation to the approach to learning}

Hypotheses regarding the relationship between the frequency of the use of specific resources which the students used to prepare for an exam or test, and the rate of the deep/surface approach were tested using the Kruskal-Wallis test. For this statistical analysis, we reduced the five-point scale, which expresses the frequency of the use of a resource, to a three-point scale, thus we obtained three groups of respondents: students with a low frequency of the use of a given resource (values 1 and 2 on a five-point scale), medium frequency of the use (value 3 ) and high frequency of the use of a resource (values 4 and 5 on a five-point scale).

As for the deep approach, significant differences based on $p$-value were not confirmed only in four resources out of twelve, namely in three most frequent resources and unverified Internet resources. The majority of resources, therefore, confirmed the assumption that there were differences in the frequency of the use of study resources in students with a different rate of the deep approach to learning. It became evident that the students with a higher rate of the deep approach used 
monographs, academic articles, course readers, dictionaries and encyclopaedias, study support and electronic courses, webinars and the like more often, but they used exam topics prepared by other students less often than the students with a lower level of the deep approach. However, the effect size in some resources was of negligible value. Table 2 presents resources for which the effect size reached at least low values, i.e., $\eta^{2}$ more than 0.01 .

On the other hand, when verifying the hypothesis regarding the relationship between the rate of the surface approach and frequency of the use of resources, the statistical analysis confirmed that the students with a higher level of the surface approach used monographs $\left(H=121.27 ; p=0.000 ; \eta^{2}=0.047 ; 1-\beta=1.000\right)$, academic articles $\left(H=70.91 ; p=0.000 ; \eta^{2}=0.028 ; 1-\beta=1.000\right)$ and course readers $(H$ $\left.=44.43 ; p=0.000 ; \eta^{2}=0.017 ; 1-\beta=1.000\right)$ less often, and exam topics prepared by classmates more often $\left(H=73.11 ; p=0.000 ; \eta^{2}=0.029 ; 1-\beta=1.000\right)$. Based on the $p$-value, the differences between the groups were also confirmed in other resources except for course readers, study support and e-courses, webinars and the like, even though the effect size was negligible $\left(\eta^{2}<0.01\right)$. Again, the assumption that there were differences in the frequency of the use of study resources in students with different levels of the surface approach to learning was confirmed in the majority of resources.

Table 2. The rate of deep approach according to the frequency of the use of resources

\begin{tabular}{|c|c|c|c|c|c|c|c|}
\hline \multirow[b]{2}{*}{ Resource } & \multicolumn{3}{|c|}{ Median } & \multirow[b]{2}{*}{$H$} & \multirow[b]{2}{*}{$p$-value } & \multirow[b]{2}{*}{$\eta^{2}$} & \multirow[b]{2}{*}{$1-\beta$} \\
\hline & $\begin{array}{c}\text { Low } \\
\text { frequency } \\
\text { of use }\end{array}$ & $\begin{array}{c}\text { Medium } \\
\text { frequency } \\
\text { of use }\end{array}$ & $\begin{array}{c}\text { High } \\
\text { frequency } \\
\text { of use }\end{array}$ & & & & \\
\hline Monographs & 3.70 & 3.80 & 4.00 & 138.18 & 0.000 & 0.048 & 1.000 \\
\hline $\begin{array}{l}\text { Academic } \\
\text { articles }\end{array}$ & 3.70 & 3.90 & 4.00 & 107.77 & 0.000 & 0.037 & 1.000 \\
\hline Textbooks & 3.70 & 3.80 & 4.00 & 85.19 & 0.000 & 0.030 & 1.000 \\
\hline $\begin{array}{l}\text { Reference } \\
\text { books }\end{array}$ & 3.80 & 3.90 & 4.00 & 63.31 & 0.000 & 0.021 & 1.000 \\
\hline Webinars, etc. & 3.80 & 3.90 & 4.00 & 44.14 & 0.000 & 0.016 & 1.000 \\
\hline Study support & 3.80 & 3.80 & 3.90 & 33.52 & 0.000 & 0.011 & 0.999 \\
\hline $\begin{array}{l}\text { Exam topics } \\
\text { prepared by } \\
\text { other students }\end{array}$ & 4.00 & 3.90 & 3.80 & 26.55 & 0.000 & 0.010 & 0.997 \\
\hline
\end{tabular}

Note: $H$ - Kruskal-Wallis test value; $p$-value at $\alpha=0.05 ; \eta 2$ - Partial Eta Squared; $1-\beta$ - statistical power 


\section{Discussion and Conclusions}

The results clearly show that the students, irrespectively of their approach to learning, preferred resources which are directly linked to the course itself: their own notes, the teacher's presentations and prepared exam topics. As for published resources, course books predominated, which are often written by teachers of these courses. Less popular resources included university textbooks and academic books, which are not that closely related to a particular course and it is necessary to select and process their content when using them. Highly specialised resources such as dictionaries, monographs and academic articles were rather neglected. These findings correspond to the results from the research surveys by Huon et al. (2007) and Pecorari (2012) and also to the findings from Horsley, Knight and Huntly (2010).

The hypotheses that there are differences in the frequency of the use of study resources in students with a different level of the deep/surface approach to learning were confirmed for the majority of resources. If we summarise our findings, it seems that the most significant differences among the students with the deep approach and surface approach were related to four resources. These differences were proven when verifying hypotheses focusing on the deep approach as well as the surface approach. The students with a higher score on the scale of the deep approach used monographs, academic articles and textbooks more often and at the same time they used exam topics prepared by classmates less often than the students with a lower score. It was the other way round for the surface approach. Approaches to learning are not only understood as student characteristics such as learning styles, but also traits which reflect the nature of teaching and learning in study programmes, at faculties or whole institutions (Biggs \& Tang, 2011). The empirical survey confirmed the relation between approaches to learning and the choice of study resources from which students prepare and it indicates important practical implications for higher education. It can be assumed that if teachers strictly require students to work - among other things - with good-quality university textbooks and academic literature, they cannot only develop students' abilities to work with an academic text and understand it but also strengthen the deep approach to learning.

\section{Acknowledgements}

The article was written within the framework of the research project The Institutional Development Programme OU IRP201823 "Education Media". 


\section{References}

Approaches and Study Skills Inventory for Students (ASSIST) (2001-2005). Enhancing Teaching-learning Environments in Undergraduate Courses (ETL Project). School of Education, University of Edinburgh, 2001-2005. Retrieved from: http://www.etl.tla.ed.ac.uk/ questionnaires/ASSIST.pdf

Biggs, J., \& Tang, C. (2011). Teaching for Quality Learning at University. Fourth Edition. New York: McGraw-Hill, Open University Press.

Byrne, M., Flood, B., \& Willis, P. (2004), Validation of the Approaches and Study Skills Inventory for Students (ASSIST) using Accounting students in the USA and Ireland: A research note", Accounting Education, 13, 449-459.

Chang, Z., Martin, V., \& Tammy, S. (2008). A cross-cultural study of Chinese and Flemish university students: Do they differ in learning conceptions and approaches to learning? Learning and Individual Differences, 18, 120-127.

Chráska, M. (2016). Metody pedagogického výzkumu [Methods of educational research]. Praha: Grada.

Diseth, A. (2001). Validation of a Norwegian version of the Approaches and Study Skills Inventory for Students (ASSIST): Application of structural equation modelling", Scandinavian Journal of Educational Research, 45(4), 381-394.

Entwistle, N., \& Ramsden, P. (1983). Understanding Student Learning. London: Croom Helm.

Entwistle, N. (2009). Teaching for Understanding at University. Deep Approaches and Distinctive Ways of Thinking. London, New York: Palgrave, Macmillan.

Entwistle, N., Tait, H., \& McCune, V. (2000). Patterns of response to an approaches to studying inventory across contrasting groups and contexts. European Journal of Psychology of Education, 15(1), :33, https://doi.org/10.1007/BF03173165

Horsley, M., \& Huntly, H. (2011). The Use of Learning Resources and Textbooks in University Courses. Central Queensland University and The Australian Publishers' Association. Tertiary and Professional Committee (Draft Report), 71pp.

Horsley, M., Knight, B., \& Huntly, H. (2010). The role of textbooks and other teaching and learning resources in higher education in Australia: change and continuity in supporting learning. IARTEM e-Journal, 3(2), 43-61.

Huon, G., Spehar, B., Adam, P., \& Rifkin, W. (2007). Resource use and academic performance among first year psychology students. Higher Education, 53, 1-27.

Marton, F., \& Säljö, R. (1997). Approaches to learning. In F. Marton, D.J. Hounsell \& N.J. Entwistle (eds.), The Experience of Learning ( $2^{\text {nd }}$ Edition), 39-58. Edinburgh: Scottish Academic Press.

Pecorari, D., Shaw, P., Irvine, A., Malstrom, H., \& Mežek, Š. (2012). Reading in Tertiary Education: Undergraduate Student Practices and Attitudes. Quality in Higher Education, $18(2), 235-256$.

Richardson, J.T.E. (2011). Eta squared and partial eta squared as measures of effect size in educational research, Educational Research Review, 6, 135-147.

Teixeira, C., Gomes, D., \& Borges, J. (2013) The approaches to studying of Portuguese students of introductory accounting. Accounting Education: An International Journal, 22, 193-210. 